\title{
Advances in dynamics and control of tethered satellite systems
}

\author{
Hao Wen · Dongping Jin · Haiyan Hu
}

Published online: 3 July 2008

(C) The Chinese Society of Theoretical and Applied Mechanics and Springer-Verlag GmbH 2008

\section{Erratum to: Acta Mech Sin}

\section{DOI:10.1007/s10409-008-0159-9}

Due to a processing error, the spelling of the author's names was incorrect. The correct names should read Dongping Jin and Haiyan $\mathrm{Hu}$

The online version of the original article can be found under doi:10.1007/s10409-008-0159-9.

H. Wen $\cdot$ D. Jin $\cdot$ H. Hu $(\bowtie)$

MOE Key Lab of Structure Mechanics and Control for Aircraft,

Nanjing University of Aeronautics and Astronautics,

210016 Nanjing, China

e-mail: hhyae@nuaa.edu.cn 